\title{
BMJ Open Effects of the COVID-19 pandemic on the follow-up and treatment of patients with idiopathic pulmonary fibrosis: a cross-sectional, multicentre phone
} call survey

\author{
Funda Coskun (D , ${ }^{1}$ Ismail Hanta, ${ }^{2}$ Aykut Cilli, ${ }^{3}$ Guven Ozkaya, ${ }^{4}$ Ahmet Ursavas, ${ }^{1}$ \\ Can Sevinc ${ }^{5}$
}

To cite: Coskun F, Hanta I, Cilli A, et al. Effects of the COVID-19 pandemic on the follow-up and treatment of patients with idiopathic pulmonary fibrosis: a crosssectional, multicentre phone call survey. BMJ Open 2021;11:e050578. doi:10.1136/ bmjopen-2021-050578

- Prepublication history and additional supplemental material for this paper are available online. To view these files, please visit the journal online. (http://dx.doi.org/10.1136/ bmjopen-2021-050578).

Received 25 February 2021 Accepted 26 July 2021
Check for updates

(c) Author(s) (or their employer(s)) 2021. Re-use permitted under CC BY-NC. No commercial re-use. See rights and permissions. Published by BMJ.

For numbered affiliations see end of article.

Correspondence to

Dr Funda Coskun;

fundacoskun@gmail.com

\section{ABSTRACT}

Objective To learn about the attitudes and behaviours of patients with idiopathic pulmonary fibrosis (IPF) in relation to the difficulties experienced during the COVID-19 pandemic.

Design A cross-sectional, multicentre phone call survey.

Setting Four university hospitals in Turkey.

Participants The study included patients with IPF receiving antifibrotics for at least 3 months and with doctor appointment and/or scheduled routine blood analysis between March and May 2020 (the first 3 months after the official announcement of the COVID-19 pandemic in Turkey).

Interventions Phone calls (a 5 min interview) were performed in June 2020. A questionnaire and the Hospital Anxiety-Depression Scale were applied.

Main outcome measures Patients' preferences for disease monitoring, patients' attitudes and behaviours towards IPF, drug continuation, COVID-19 diagnosis and anxiety/depression status.

Results The study included 115 patients with IPF (82 male; mean age, $68.43 \pm 7.44$ years). Of the patients, $73.9 \%$ had doctor appointment and $52.2 \%$ had scheduled routine blood testing; $54.5 \%$ of patients with doctor appointment self-cancelled their appointments and $53.3 \%$ of patients with scheduled routine blood testing did not undergo testing. Of the patients, $32.2 \%$ were on nintedanib and $67.8 \%$ were on pirfenidone; self-initiated drug discontinuation rate was $22.6 \%$. The percentage of patients communicating with their physicians was $35.7 \%$. The route of communication was by phone $(34.8 \%)$. The frequency of depression and anxiety was $27.0 \%$ and $38.3 \%$, respectively. The rates of drug discontinuation $(35.1 \%$ vs $16.7 \%, \mathrm{p}<0.05)$ and depression $(37.8 \%$ vs $21.8 \%, p=0.07)$ were higher in nintedanib users than in pirfenidone users. Only two (1.7\%) patients had COVID-19 diagnosis.

Conclusions During the COVID-19 pandemic, a significant proportion ( $>50 \%$ ) of patients self-cancelled their appointments and nearly a quarter of patients discontinued their medications. Providing a documentation of the problems experienced by patients with IPF about management of the necessary requirements during

\section{STRENGTHS AND LIMITATIONS OF THIS STUDY}

$\Rightarrow$ This study is the first to assess the effects of the COVID-19 pandemic on patients with idiopathic pulmonary fibrosis (IPF).

$\Rightarrow$ This study has strength in that it is a cross-sectional, multicentre study using random method.

$\Rightarrow$ Medication use of patients with IPF was evaluated simultaneously with patients' anxiety and depression status through a questionnaire survey.

$\Rightarrow$ This study was limited in that the side effects of patients with IPF were not questioned in detail.

$\Rightarrow$ This study was limited due to lack of data on patients' anxiety and depression status before the pandemic.

the COVID-19 pandemic, this study may be a model for patients with chronic diseases.

\section{INTRODUCTION}

Following the announcement of the first case at the end of December 2019 in China, COVID-19 has affected the entire world and was declared a pandemic by the WHO. The first case of COVID-19 in Turkey was officially announced on 11 March 2020. From that period, attempts to stop the spread of COVID-19 have been done through various strict restrictions. Necessary requirements for individuals with chronic diseases, such as hospital visits, routine controls, access to medicines and switching medications, were affected due to these restrictions, as well as fear of going outside and the tendency to avoid visiting healthcare facilities. It is not yet known in what way this situation influences the course of chronic diseases.

In idiopathic pulmonary fibrosis (IPF), which is one of the chronic pulmonary diseases, patients are generally evaluated 
every 3 months for respiratory symptoms, respiratory function tests, blood tests and radiological examinations. Thus, it is essential for patients to visit healthcare centres. According to the guidelines during the COVID-19 pandemic, unless there is a change in their disease status, patients with chronic diseases are generally recommended to postpone their control visits and to have their disease course evaluated by contacting their physicians via communication tools. ${ }^{1}$ The present study aimed to learn about the attitudes and behaviours of patients with IPF in relation to the difficulties that they experienced during the COVID-19 pandemic.

\section{METHODS}

The present cross-sectional, multicentre phone call survey included patients with IPF who were on antifibrotic therapy for at least 3 months with a diagnosis of IPF and had doctor appointment and/or were scheduled for a routine blood analysis between March 2020 and May 2020, which corresponds to the first 3 months after the official announcement of the COVID-19 pandemic in Turkey on 11 March 2020. The study was conducted in four university hospitals (Dokuz Eylul University-Izmir, Akdeniz University-Antalya, Bursa Uludag UniversityBursa and Cukurova University-Adana). A statistical power analysis was performed for sample size estimation based on the 2018 consensus report for diagnosis and treatment of IPF by Ergur et $a l^{2}{ }^{2}$ Sample size was calculated using the formula for cross-sectional studies. Assuming an error margin of $4 \%$ and a CI of $95 \%$, a sample size of 28 patients was required for each university hospital. Accordingly, a total of 115 patients were selected among 322 patients with IPF fulfilling the study inclusion criteria using the patient list via systematic random sampling. All patients who were called for the survey answered the questionnaire.

Diagnosis of IPF was established based on the 2018 American Thoracic Society/European Respiratory Society/Japanese Respiratory Society/Latin American Thoracic Society guideline. ${ }^{3}$ The study protocol is provided in online supplemental file 1 .

Patients were contacted by phone in June 2020. A questionnaire was applied to understand patients' preferences for disease monitoring and their attitudes and behaviours towards their disease during the COVID-19 pandemic. In addition, information about symptoms, presence of COVID-19 diagnosis and hospitalisation was also enquired in the same phone call.

The Hospital Anxiety-Depression Scale (HADS), the reliability and validity of which have been evaluated in Turkish language, was used to assess patients' depression and anxiety. ${ }^{45}$ The HADS is a 14-item scale assessing patients' mood. The questions with odd numbers measure anxiety, whereas the questions with even numbers measure depression. A total anxiety score of 10 indicates the presence of anxiety and a total depression score of 7 indicates the presence of depressive mood. The whole scale takes
2-3 min to complete and the questionnaire takes $2 \mathrm{~min}$ to complete; thus, the data were collected via a $5 \mathrm{~min}$ phone interview. The questionnaire used to collect data for the present study is provided in online supplemental file 2.

Patients' data that were recorded in the hospital files before their inclusion in the study were used to assess duration of medication use and severity of disease. Severity of IPF was assessed using the Gender-Age-Physiology (GAP) index, where the physiology variables include forced vital capacity (FVC) and diffusing capacity of the lungs for carbon monoxide (DLCO) ${ }^{6}$

Informed consent for participation in the study was obtained from all patients.

\section{Patient and public involvement}

There is no patient and public involvement in this research.

\section{Statistical analysis}

Data analyses were performed using IBM SPSS Statistics for Windows V.23.0. Descriptive statistics were expressed as mean and SD for quantitative data and as frequency and percentage for qualitative data. Categorical data were analysed by Pearson's $\chi^{2}$ test and Fisher's exact $\chi^{2}$ test. The level of significance was set at $\alpha=0.05$.

\section{RESULTS}

A total of 115 patients were randomly selected among 322 patients with IPF with scheduled follow-up appointment between March 2020 and May 2020. Of the patients, 82 $(71.3 \%)$ were male and $33(28.7 \%)$ were female. The mean age of the patients was $68.43 \pm 7.44$ years and the mean disease duration was $20.94 \pm 17.88$ months. The mean duration on antifibrotic therapies for the study patients was $18.50 \pm 12.30$ months. According to the GAP index, $54(47 \%)$ of patients were in GAP stage I, $51(44 \%)$ were in GAP stage II, and $10(9 \%)$ were in GAP stage III. Of the patients, $37(32.2 \%)$ were on nintedanib and 78 $(67.8 \%)$ were on pirfenidone. The general characteristics of the patients are presented in table 1.

In this study, $73.9 \%$ of the patients had doctor appointment and 52.2\% had scheduled routine blood testing. Of the patients with doctor appointment, while $15.4 \%$ attended their control visits, $54.5 \%$ self-cancelled their appointments and $30 \%$ postponed their appointments after discussing with their physicians. Of the patients with scheduled routine blood testing, 53.3\% did not undergo testing. The percentage of patients who were able to reach their treating physician remained low by $35.7 \%$. Of the patients, $34.8 \%$ contacted their physicians via phone calls. It was observed that $22.6 \%$ of the patients discontinued their medications on their own decisions. Moreover, $45.2 \%$ of the patients were able to reach their treating physicians in case of worsened complaints. Of the patients with complaints, $32.2 \%$ did not visit a healthcare centre due to fear of COVID-19 and waited for their 
Table 1 General characteristics of the study patients

\begin{tabular}{|c|c|}
\hline Characteristics & $\begin{array}{l}\text { Patients with } \\
\text { IPF } \\
\mathrm{N}=115\end{array}$ \\
\hline Age, years, mean $\pm S D$ & $68.43 \pm 7.44$ \\
\hline \multicolumn{2}{|l|}{ Sex, n (\%) } \\
\hline Female & $33(28.7)$ \\
\hline Male & $82(71.3)$ \\
\hline Disease duration, months, mean \pm SD & $20.94 \pm 17.88$ \\
\hline FVC (\%), mean \pm SD & $73.18 \pm 20.31$ \\
\hline DLCO (\%), mean \pm SD & $53.12 \pm 16.94$ \\
\hline \multicolumn{2}{|l|}{ GAP index, n (\%) } \\
\hline Stage I & $54(47)$ \\
\hline Stage II & $51(44)$ \\
\hline Stage III & $10(9)$ \\
\hline $\begin{array}{l}\text { Duration on antifibrotic therapies, months, } \\
\text { mean } \pm \text { SD }\end{array}$ & $18.50 \pm 12.30$ \\
\hline \multicolumn{2}{|l|}{ Medications, n (\%) } \\
\hline Pirfenidone & $78(67.8)$ \\
\hline Nintedanib & $37(32.2)$ \\
\hline $\begin{array}{l}\text { DLCO, diffusing capacity of the lungs for carbon } \\
\text { FVC, forced vital capacity; GAP, Gender-Age-Phy } \\
\text { (physiology variables: FVC and DLCO); IPF, idiop } \\
\text { fibrosis. }\end{array}$ & $\begin{array}{l}\text { monoxide; } \\
\text { siology index } \\
\text { athic pulmonary }\end{array}$ \\
\hline
\end{tabular}

complaints to disappear. Patients' responses to the study questionnaire are presented in table 2.

In the present study, the frequency of depression and anxiety was found to be $27.0 \%$ and $38.3 \%$, respectively. The frequency of anxiety and depression was higher in patients who discontinued their medications $(p<0.05$ for both; table 3). Depression was detected in $37.8 \%$ of patients receiving nintedanib and in $21.8 \%$ of patients receiving pirfenidone; the difference was close to the level of statistical significance $(\mathrm{p}=0.07)$. Drug discontinuation rate was $35.1 \%$ in patients using nintedanib and $16.7 \%$ in patients using pirfenidone $(p<0.05)$. When patients were questioned about the side effects of medications, $73.9 \%$ reported no side effects. The most common side effect was reported as gastrointestinal system complaints $(n=17$; $26.1 \%)$. Only two $(1.7 \%)$ patients were diagnosed with COVID-19.

\section{DISCUSSION}

IPF is the chronic, progressive, fatal form of disseminated interstitial lung disease (ILD). The management of IPF requires continuous and systematic approach including not only regular controls but also implementation of both pharmacological and non-pharmacological treatments. ${ }^{7}$ Patients with IPF are followed at regular intervals from the time of diagnosis. Regular monitoring is recommended for medications, management of side effects, and identification and treatment of comorbidities. A
Table 2 Responses of patients to the study questionnaire

\begin{tabular}{ll} 
& Patients with \\
& IPF \\
Responses & $\mathrm{N}=115$ \\
\hline
\end{tabular}

Having a control visit during the pandemic period $^{\star}, \mathrm{n}(\%)$

Present

Absent

Having a scheduled blood analysis during the pandemic period*, n (\%)

Present

Absent

Blood analysis during the pandemic period*, n (\%)

\begin{tabular}{lc} 
Having no scheduled blood testing & $55(47.8)$ \\
$\begin{array}{l}\text { Having a scheduled blood testing but not } \\
\text { going for testing }\end{array}$ & $32(27.8)$ \\
$\begin{array}{l}\text { Having had the blood testing in a } \\
\text { healthcare centre }\end{array}$ & $18(15.7)$ \\
$\begin{array}{l}\text { Not having had the blood testing after } \\
\text { discussing with the treating physician }\end{array}$ & $10(8.7)$ \\
$\begin{array}{l}\text { Doctor appointment during the pandemic } \\
\text { eriod*, n (\%) }\end{array}$ & $5(4.3)$ \\
$\begin{array}{l}\text { Having no doctor appointment } \\
\text { Having doctor appointment but not } \\
\text { attending due to COVID-19 fear }\end{array}$ & $60(52.2)$ \\
$\begin{array}{l}\text { Postponed after discussing with treating } \\
\text { physician }\end{array}$ & $33(28.7)$ \\
$\begin{array}{l}\text { Having attended the appointment } \\
\text { Having contacted the treating physician } \\
\text { uring the pandemic period*, n (\%) }\end{array}$ & $17(14.8)$ \\
\hline $\begin{array}{l}\text { Present } \\
\text { Absent }\end{array}$ & $41(35.7)$ \\
\hline $\begin{array}{l}\text { Soute of communication, n (\%) } \\
\text { Phone }\end{array}$ & $74(64.3)$ \\
\hline
\end{tabular}

Drug continuation during the pandemic period $^{*}, \mathrm{n}(\%)$

Present

Absent

Worsened complaints during the pandemic period $^{*}, \mathrm{n}(\%)$

Having no complaints
Having reached the treating physician
Unable to reach the treating physician and
therefore visiting a healthcare centre
Not having visited a healthcare centre due
to fear and thus having waited

$9(7.8)$

37 (32.2) Side effects related to antifibrotic drugs, $\mathrm{n}$ (\%) 
Table 2 Continued

\begin{tabular}{|c|c|}
\hline Responses & $\begin{array}{l}\text { Patients with } \\
\text { IPF } \\
\text { N=115 }\end{array}$ \\
\hline Present & $30(26.1)$ \\
\hline Absent & 85 (73.9) \\
\hline \multicolumn{2}{|c|}{ Having diagnosed with COVID-19, n (\%) } \\
\hline Present & $2(1.7)$ \\
\hline Absent & $113(98.3)$ \\
\hline \multicolumn{2}{|l|}{ Anxiety status, n (\%) } \\
\hline Abnormal +borderline & $44(38.3)$ \\
\hline Normal & $71(61.7)$ \\
\hline \multicolumn{2}{|l|}{ Depression status, n (\%) } \\
\hline Abnormal+ borderline & $31(27.0)$ \\
\hline Normal & $84(73.0)$ \\
\hline \multicolumn{2}{|c|}{$\begin{array}{l}\text { *In the present study, the pandemic period includes the period } \\
\text { between March } 2020 \text { and May } 2020 \text {, which corresponds to the } \\
\text { first } 3 \text { months after the official announcement of the COVID-19 } \\
\text { pandemic in Turkey. } \\
\text { IPF, idiopathic pulmonary fibrosis. }\end{array}$} \\
\hline
\end{tabular}

follow-up interval of 3-6 months has been implemented in earlier studies. ${ }^{78}$ Fernández Fabrellas et a $\ell^{9}$ suggested a follow-up interval of up to 6 months in mild cases and a follow-up interval of 3 months in cases with moderatesevere disease. Symptom enquiry, history of hospitalisation, FVC and DLCO findings, 6 min walk test, oxygen saturation by pulse oximetry, and based on patients' condition high-resolution thoracic CT scans and/or echocardiography should be carefully examined during follow-ups. Biomarkers have not been included in routine blood analyses yet. However, routine blood analyses such as renal and hepatic function tests and complete blood count are performed to assess side effects particularly in patients receiving medications. ${ }^{9}$

The COVID-19 pandemic has caused massive upheaval in health systems and rapid changes in healthcare delivery worldwide. In the context of ILD, the COVID-19 pandemic has paralysed comprehensive examinations of patients, particularly for those newly diagnosed, and made the monitoring of potential side effects difficult by affecting access to various medications. An important issue while initiating or maintaining treatment for IPF is monitoring blood parameters in patients receiving antifibrotic drugs. Close monitoring and periodic blood analyses are mandatory due to potential complications (such as hepatotoxicity) in cases initiated on antifibrotic medications for IPF. Reducing the frequency of patient follow-up may be appropriate during the COVID-19 pandemic in patients receiving treatment for chronic ILD. ${ }^{1}$

Within the scope of our routine clinical practice, patients with IPF who are new to drug therapy are followed initially at 15-day intervals and then at 3-month intervals at most. During these control visits, patients are evaluated by enquiring adherence to drugs, changes in symptoms and presence of side effects and by performing respiratory function tests and blood analyses. In the first 3 months after the official announcement of the COVID-19 pandemic in Turkey, the period during which the present study was conducted, all routine healthcare services, including those provided in the clinics of the study, were almost suspended. After the first case of COVID-19 was confirmed in Turkey in March 2020, the country entered a general lockdown and healthcare services were continued only for COVID-19 cases; only emergency services were provided for other diseases. During this period, the entire health system starting from the primary healthcare level focused on understanding COVID-19 and diagnosing and treating existing patients. In April and May 2020, primary care and hospital services were available for all patients. However, it was observed in the present study that $80.9 \%$ of our patients with IPF did not attend their doctor appointments despite available primary care and hospital services. During the study period, a telemedicine approach was not used in the clinics included in the present study. It is obvious that a proactive approach for telemedicine should be adopted by the health system in Turkey. In the first randomised controlled trial in which a 24-week electronic health (eHealth) programme was used in patients with IPF, it was demonstrated that a home monitoring programme alone did not significantly improve patients' quality of life assessed by the King's Brief Interstitial Lung Disease questionnaire as compared with standard care. ${ }^{10}$ However, after 24 weeks, psychological well-being tended to improve and general well-being was substantially higher in the home monitoring group. ${ }^{10}$ Additionally, it was also demonstrated that home monitoring was appreciated by the patients, provided arrangements for patient-specific treatments and did not increase anxiety levels assessed by the HADS. ${ }^{10}$ Nevertheless, the pandemic offers opportunities for improving approaches such as widespread adoption of telemedicine.

In the present study, it was observed that $60(54.5 \%)$ of 110 patients with a doctor appointment during the pandemic period (the first 3 months after the official announcement of the COVID-19 pandemic in Turkey) did not visit their physicians on their own decisions and that $32(53.3 \%)$ of 60 patients having blood analyses testing did not undergo testing. Considering our routine clinical practice, it could be suggested that these percentages were quite high. Moreover, $64.3 \%$ of the patients were unable to contact their treating physicians, and $40(97.6 \%)$ of 41 patients were able to contact their treating physicians via phone calls. It is obvious during the pandemic period that patients with chronic diseases should be informed about the potential problems of this period, necessary actions should be taken for follow-up of patients, and routes of communication should be specified. In the present study, $37(58.7 \%)$ of 63 patients did not visit a healthcare centre despite their worsened disease-related complaints. In addition, 26 (22.6\%) of the 
Table 3 Characteristics of patients according to their anxiety and depression status

\begin{tabular}{|c|c|c|c|c|}
\hline \multirow[b]{2}{*}{ Characteristics } & \multicolumn{2}{|l|}{ Anxiety } & \multicolumn{2}{|l|}{ Depression } \\
\hline & $\begin{array}{l}\text { Abnormal+ borderline } \\
\text { n (\%) }\end{array}$ & $\begin{array}{l}\text { Normal } \\
\text { n (\%) }\end{array}$ & $\begin{array}{l}\text { Abnormal+ borderline } \\
\text { n (\%) }\end{array}$ & $\begin{array}{l}\text { Normal } \\
\text { n (\%) }\end{array}$ \\
\hline \multicolumn{5}{|l|}{ Blood analysis during the pandemic period* } \\
\hline Having no scheduled blood testing & $22(40.0)$ & $33(60.0)$ & $11(20.0)$ & $44(80.0)$ \\
\hline $\begin{array}{l}\text { Having a scheduled blood testing but not going for } \\
\text { testing }\end{array}$ & $14(43.8)$ & $18(56.3)$ & $13(40.6)$ & $19(59.4)$ \\
\hline Having had the blood testing in a healthcare centre & $3(16.7)$ & $15(83.3)$ & $2(11.1)$ & $16(88.9)$ \\
\hline $\begin{array}{l}\text { Not having had the blood testing after discussing } \\
\text { with treating physician }\end{array}$ & $5(50.0)$ & $5(50.0)$ & $5(50.0)$ & $5(50.0)$ \\
\hline$P$ value & 0.202 & & $0.023^{*}$ & \\
\hline \multicolumn{5}{|l|}{ Doctor appointment during the pandemic period* } \\
\hline Having no doctor appointment & $1(20.0)$ & $4(80.0)$ & $1(20.0)$ & $4(80.0)$ \\
\hline $\begin{array}{l}\text { Having doctor appointment but not attending due } \\
\text { to fear }\end{array}$ & $18(30.0)$ & $42(70.0)$ & $15(25.0)$ & $45(75.0)$ \\
\hline $\begin{array}{l}\text { Postponing appointment after discussing with } \\
\text { treating physician }\end{array}$ & $17(51.5)$ & $16(48.5)$ & $11(33.3)$ & $22(66.7)$ \\
\hline Having attended the appointment & $8(47.1)$ & 9 (52.9) & $4(23.5)$ & $13(76.5)$ \\
\hline$P$ value & 0.136 & & 0.835 & \\
\hline \multicolumn{5}{|l|}{$\begin{array}{l}\text { Having contacted the treating physician during the } \\
\text { pandemic period* }\end{array}$} \\
\hline Present & $19(46.3)$ & $22(53.7)$ & $13(31.7)$ & $28(68.3)$ \\
\hline Absent & $25(33.8)$ & $49(66.2)$ & $18(24.3)$ & $56(75.7)$ \\
\hline$P$ value & 0.184 & & 0.393 & \\
\hline \multicolumn{5}{|l|}{ Drug continuation during the pandemic period* } \\
\hline Present & $28(31.5)$ & $61(68.5)$ & $16(18.0)$ & $73(82.0)$ \\
\hline Absent & $16(61.5)$ & $10(38.5)$ & $15(57.7)$ & $11(42.3)$ \\
\hline$P$ value & $0.006^{*}$ & & $<0.001^{*}$ & \\
\hline \multicolumn{5}{|l|}{ Worsened complaints during the pandemic period* } \\
\hline Having no complaints & $18(34.6)$ & $34(65.4)$ & $8(15.4)$ & $44(84.6)$ \\
\hline Having reached the treating physician & $9(52.9)$ & $8(47.1)$ & $9(52.9)$ & $8(47.1)$ \\
\hline $\begin{array}{l}\text { Unable to reach the treating physician and } \\
\text { therefore visiting any healthcare centre }\end{array}$ & $5(55.6)$ & $4(44.4)$ & $5(55.6)$ & $4(44.4)$ \\
\hline $\begin{array}{l}\text { Not having visited a healthcare centre due to fear } \\
\text { and thus having waited }\end{array}$ & $12(32.4)$ & $25(67.6)$ & $9(24.3)$ & $28(75.7)$ \\
\hline$P$ value & 0.319 & & $0.004^{*}$ & \\
\hline
\end{tabular}

*Statistically significant $p<0.05$

*In the present study, the pandemic period includes the period between March 2020 and May 2020, which corresponds to the first 3 months after the official announcement of the COVID-19 pandemic in Turkey.

overall study patients $(\mathrm{N}=115)$ discontinued their medications on their own decisions.

Depression and anxiety in patients with IPF have been reported at varying frequencies from $36.4 \%$ to $42.9 \%$ for the prepandemic period. ${ }^{11}{ }^{12}$ Depression and anxiety in patients with IPF are associated with severity of disease. ${ }^{13}$ In their study, Lee et $a l^{14}$ reported that depression was present in $25.9 \%$ of patients with IPF but that depression was not related to hospitalisation or mortality. Glaspole $e t$ $a l^{15}$ reported the frequency of anxiety and depression in patients with IPF to be $31 \%$ and $23 \%$, respectively, and found depression to be associated with dyspnoea and cough. Akhtar et $_{\text {al }}{ }^{16}$ identified an increase in depression score by $49.2 \%$ in patients with IPF. To the best of our knowledge, there is no study investigating depression or anxiety in patients with IPF during the COVID-19 pandemic in the literature. In the present study, the frequency of depression and anxiety in patients with IPF during the pandemic period were found to be $27 \%$ and $38.3 \%$, respectively. These frequencies were consistent with the frequencies in the prepandemic period; thus, 
no significant increase was detected in the depression or anxiety scores of patients with IPF due to the pandemic.

Reasons for drug discontinuation were not enquired in detail in the present study. Although side effects appear the most common causes of drug discontinuation among patients with chronic diseases in the literature, questioning the side effects in the present study revealed mild side effects, with the most common being gastrointestinal complaints reported by only $26.1 \%$ of the patients. Nevertheless, it was observed that the frequency of depression and anxiety was higher in patients who discontinued their medications $(\mathrm{p}<0.05$ for both $)$. In their meta-analysis, Cheen $e t a l^{17}$ reported the frequency of medication nonadherence in chronic diseases to be $17 \%$ and found the reasons for non-adherence to medications were young age, use of concurrent medications, medications being prescribed by general practitioners and high-cost medications. ${ }^{17}$ In the study on adherence to medications in older adults by Yap et al, ${ }^{18}$ it was demonstrated that mental state, depression, lower cognitive function, poor memory, anxiety and sleep disturbances had an effect on adherence to medications. Poor adherence to medications observed in the present study might be due to the facts that our patient group was old (mean age, 68.43 \pm 7.44 years) and their depression and anxiety levels were high due to the COVID-19 pandemic.

An analysis of pooled data from studies on pirfenidone in patients with IPF revealed a drug discontinuation rate of $15.6 \%$ in a year. ${ }^{19}$ Wuyts $e t a l^{8}$ reported a drug discontinuation rate of $4.6 \%$ in a real-world population of patients with IPF. A pooled analysis of data from studies on nintedanib revealed a drug discontinuation rate of $20.6 \%$ in patients with IPF. ${ }^{20}$ These studies were 12 -month studies. In the present study, the drug discontinuation rate in patients using pirfenidone was $16.7 \%$, which was consistent with the pooled data. The drug discontinuation rate $(35.1 \%)$ of patients using nintedanib in the present study was higher than the rates reported in the literature. The rate of depression was found higher in patients receiving nintedanib $(37.8 \%)$ than in patients receiving pirfenidone $(21.8 \%)$, with the difference being close to the level of statistical significance $(p=0.07)$. Accordingly, the high drug discontinuation rate observed in the nintedanib group could be attributed to the finding that the patients using nintedanib were so close to depression.

Drug exposure time also needs to be evaluated while assessing drug discontinuation rates. Studies have demonstrated that drug discontinuation is higher in the first 6 months due to the higher rates of side effects. ${ }^{20}{ }^{21}$ The patients included in the present study were patients receiving drug therapy for at least 3 months and having a mean disease duration of 20 months. Accordingly, it could be suggested that a higher self-initiated drug discontinuation rate $(22.6 \%)$ was found in the present study for a period of 3-6months as compared with the rates reported in the literature.

Only $1.7 \%$ of our patients were diagnosed with COVID19. The percentage of patients who did not attend doctor visits and/or undergo routine blood testing was high in the present study. Thus, it could be suggested that our patients protected themselves against COVID-19 by staying at home.

The present study has some limitations. One of the limitations was the absence of information on patients' anxiety and depression status before the pandemic. Therefore, the findings during the pandemic period could not be compared with the findings during the prepandemic period for the study population; however, the findings were discussed as compared with the results of earlier studies. Another limitation could be not enquiring the reasons for drug discontinuation. Moreover, not evaluating the long-term outcomes of the attitudes and behaviours of patients could also be considered another limitation. We did not obtain this information since this was a cross-sectional study and these were not among the objectives of the study.

In conclusion, during the COVID-19 pandemic period defined in the present study, more than half of the patients with a doctor appointment self-cancelled their appointments and nearly a quarter of the patients discontinued their medications. The rate of drug discontinuation was higher in patients receiving nintedanib. Moreover, the frequency of depression was higher among nintedanib users with borderline significance, which indicated that depression could be the reason for drug discontinuation in nintedanib users. The frequency of depression and anxiety was found to be consistent with that reported in the literature for patients with IPF; we are in the opinion that the COVID-19 pandemic did not lead to a change in depression and anxiety status of patients with IPF. Another outcome of the present study was the objective documentation of the problems experienced by our patients during the COVID-19 pandemic, such as problems related to being informed, access to treating physicians, management of side effects and drug continuation. Conclusively, the present study is different from other studies in that the study aimed at identifying behaviour patterns of cases with chronic diseases during the pandemic period. Patients with chronic diseases like IPF may also have similar behaviour patterns; thus, this study may be a model for patients with other chronic diseases. In addition, the necessity of adoption of eHealth applications in the practice of medicine has become prominent during the COVID-19 pandemic. The COVID-19 pandemic has once again shown that alternative ways for monitoring patients with chronic diseases such as IPF should be considered and implemented.

\section{Author affiliations}

${ }^{1}$ Department of Chest Diseases, Bursa Uludag University, Bursa, Turkey ${ }^{2}$ Department of Chest Diseases, Cukurova University Faculty of Medicine, Adana, Turkey

${ }^{3}$ Department of Chest Diseases, Akdeniz University Medical School, Antalya, Turkey ${ }^{4}$ Department of Biostatistics, Bursa Uludag University, Bursa, Turkey ${ }^{5}$ Department of Chest Diseases, Dokuz Eylul University Faculty of Medicine, Izmir, Turkey 
Contributors FC and IH contributed to planning and implementation of the study and writing and editing of the manuscript. AC, AU and CS contributed to implementation of the study and editing and peer review of the manuscript. GO performed the analysis and interpretation of data and contributed to the writing of the manuscript.

Funding The authors have not declared a specific grant for this research from any funding agency in the public, commercial or not-for-profit sectors.

Competing interests $\mathrm{FC}, \mathrm{IH}, \mathrm{AC}, \mathrm{AU}$ and $\mathrm{CS}$ have acted as consultant and/or speaker in the congress for Boehringer Ingelheim, Roche and Nobel.

Patient consent for publication Not required.

Ethics approval The study was approved by the Ethics Committee of Bursa Uludag University (date: 13 May 2020; approval number 2020-8/12).

Provenance and peer review Not commissioned; externally peer reviewed.

Data availability statement Data are available upon reasonable request. The datasets generated during and/or analyzed during the present study are available from the corresponding author upon reasonable request.

Supplemental material This content has been supplied by the author(s). It has not been vetted by BMJ Publishing Group Limited (BMJ) and may not have been peer-reviewed. Any opinions or recommendations discussed are solely those of the author(s) and are not endorsed by BMJ. BMJ disclaims all liability and responsibility arising from any reliance placed on the content. Where the content includes any translated material, BMJ does not warrant the accuracy and reliability of the translations (including but not limited to local regulations, clinical guidelines, terminology, drug names and drug dosages), and is not responsible for any error and/or omissions arising from translation and adaptation or otherwise.

Open access This is an open access article distributed in accordance with the Creative Commons Attribution Non Commercial (CC BY-NC 4.0) license, which permits others to distribute, remix, adapt, build upon this work non-commercially, and license their derivative works on different terms, provided the original work is properly cited, appropriate credit is given, any changes made indicated, and the use is non-commercial. See: http://creativecommons.org/licenses/by-nc/4.0/.

\section{ORCID iD}

Funda Coskun http://orcid.org/0000-0003-3604-8826

\section{REFERENCES}

1 Wong AW, Fidler L, Marcoux V, et al. Practical considerations for the diagnosis and treatment of fibrotic interstitial lung disease during the coronavirus disease 2019 pandemic. Chest 2020;158:1069-78.

2 Ergur GA, Bingöl Z, ÖÖ K. Türk Toraks Derneği Idiyopatik Pulmoner fibrosis Tanı ve Tedavi Uzlaşı Raporu 2018. 2018. Kavaklıdere, Ankara: Bilimsel Tıp Yayınevi, 2018.

3 Raghu G, Remy-Jardin M, Myers JL, et al. Diagnosis of idiopathic pulmonary fibrosis. An official ATS/ERS/JRS/ALAT clinical practice guideline. Am J Respir Crit Care Med 2018;198:e44-68.
4 Zigmond AS, Snaith RP. The hospital anxiety and depression scale. Acta Psychiatr Scand 1983;67:361-70.

5 Aydemir O, Guvenir T, Küey L. Validity and reliability of Turkish version of hospital anxiety and depression scale. Turk Psikiyatri Derg 1997;8:280-8.

6 Ley B, Ryerson CJ, Vittinghoff E, et al. A multidimensional index and staging system for idiopathic pulmonary fibrosis. Ann Intern Med 2012;156:684-91.

7 Egan JJ. Follow-up and nonpharmacological management of the idiopathic pulmonary fibrosis patient. Eur Respir Rev 2011;20:114-7.

8 Wuyts WA, Dahlqvist C, Slabbynck $\mathrm{H}$, et al. Longitudinal clinical outcomes in a real-world population of patients with idiopathic pulmonary fibrosis: the proof registry. Respir Res 2019;20:231.

9 Fernández Fabrellas E, Peris Sánchez R, Sabater Abad C, et al. Prognosis and follow-up of idiopathic pulmonary fibrosis. Med Sci 2018;6:51.

10 Moor CC, Mostard RLM, Grutters JC, et al. Home monitoring in patients with idiopathic pulmonary fibrosis. A randomized controlled trial. Am J Respir Crit Care Med 2020;202:393-401.

11 Tzouvelekis A, Karampitsakos T, Kourtidou S, et al. Impact of depression on patients with idiopathic pulmonary fibrosis. Front Med 2020;7:29.

12 Janssen K, Rosielle D, Wang Q, et al. The impact of palliative care on quality of life, anxiety, and depression in idiopathic pulmonary fibrosis: a randomized controlled pilot study. Respir Res 2020;21:2.

13 Matsuda T, Taniguchi $\mathrm{H}$, Ando $\mathrm{M}$, et al. Depression is significantly associated with the health status in patients with idiopathic pulmonary fibrosis. Intern Med 2017;56:1637-44.

14 Lee YJ, Choi SM, Lee YJ, et al. Clinical impact of depression and anxiety in patients with idiopathic pulmonary fibrosis. PLoS One 2017;12:e0184300.

15 Glaspole IN, Watson AL, Allan H, et al. Determinants and outcomes of prolonged anxiety and depression in idiopathic pulmonary fibrosis. Eur Respir J 2017;50:1700168.

16 Akhtar AA, Ali MA, Smith RP. Depression in patients with idiopathic pulmonary fibrosis. Chron Respir Dis 2013;10:127-33.

17 Cheen MHH, Tan YZ, Oh LF, et al. Prevalence of and factors associated with primary medication non-adherence in chronic disease: a systematic review and meta-analysis. Int J Clin Pract 2019;73:e13350.

18 Yap AF, Thirumoorthy T, Kwan YH. Systematic review of the barriers affecting medication adherence in older adults. Geriatr Gerontol Int 2016;16:1093-101.

19 Noble PW, Albera C, Bradford WZ, et al. Pirfenidone for idiopathic pulmonary fibrosis: analysis of pooled data from three multinational phase 3 trials. Eur Respir J 2016;47:243-53.

20 Richeldi L, Cottin V, du Bois RM, et al. Nintedanib in patients with idiopathic pulmonary fibrosis: Combined evidence from the TOMORROW and INPULSIS(®) trials. Respir Med 2016;113:74-9.

21 Cottin V, Koschel D, Günther A, et al. Long-term safety of pirfenidone: results of the prospective, observational PASSPORT study. ERJ Open Res 2018;4:00084-2018. 